\title{
Adsorption Cooling System Using Metal-Impregnated Zeolite-4A
}

\author{
Somsuk Trisupakitti, Jindaporn Jamradloedluk, and Songchai Wiriyaumpaiwong \\ Faculty of Mechanical Engineering, Mahasarakham University, Kantharawichai District, Maha Sarakham 44150, Thailand \\ Correspondence should be addressed to Somsuk Trisupakitti; somsuk_rmu@yahoo.com
}

Received 28 February 2016; Revised 19 May 2016; Accepted 19 May 2016

Academic Editor: Luigi Nicolais

Copyright (C) 2016 Somsuk Trisupakitti et al. This is an open access article distributed under the Creative Commons Attribution License, which permits unrestricted use, distribution, and reproduction in any medium, provided the original work is properly cited.

\begin{abstract}
The adsorption cooling systems have been developed to replace vapor compression due to their benefits of being environmentally friendly and energy saving. We prepared zeolite-4A and experimental cooling performance test of zeolite-water adsorption system. The adsorption cooling test-rig includes adsorber, evaporator, and condenser which perform in vacuum atmosphere. The maximum and minimum water adsorption capacity of different zeolites and COP were used to assess the performance of the adsorption cooling system. We found that loading zeolite-4A with higher levels of silver and copper increased COP. The Cu6\%/zeolite-4A had the highest COP at 0.56 while COP of zeolite- $4 \mathrm{~A}$ alone was 0.38 . Calculating the acceleration rate of zeolite- $4 \mathrm{~A}$ when adding $6 \%$ of copper would accelerate the COP at $46 \%$.
\end{abstract}

\section{Introduction}

Cooling systems play important roles in our daily life like food preservation, air-conditioning system, and medical treatment. However, popular vapor compression refrigeration systems have a destructive effect on the global environment-the greenhouse effect [1]. This damages the ozone level in Earth's atmosphere, due to emission of HFCs, HCFCs, and CFCs commonly used in vapor compression systems, and use of these refrigerants is perceived as a critical contributor to global warming [1]. Therefore, alternative adsorption cooling systems may help to reduce the greenhouse effect and this alternative technology has some additional benefits as it can use waste heat sources including solar power, industrial factories, or automobiles $[1,2]$.

Adsorption cooling systems are environmentally friendly in that the system does not destroy ozone and add to global warming [2] because an adsorption cooling system uses natural refrigerants such as water, ammonia, methanol, and ethanol. However, there are some disadvantages. Adsorption systems cool in a noncontinuous cycle and the adsorption rate between the working pairs is not constant. That is, in the initial stage, the adsorption rate is fast as the surface area of adsorbent is adequate, but, after some time, the working pairs reach equilibrium and the surface area is fully occupied. So the working substance cannot reach the inner regions of adsorbent and thus leads to slower adsorption rate. This directly leads to low Coefficient of Performance (COP). There are two ways to solve these problems. One is to develop a new adsorbent which has better adsorption capacity. The other is to improve the physical structure of adsorbent. The zeolitewater pair is generally regarded as one of the most suitable adsorbent-adsorbate pairs in these devices [1-3].

Accordingly, researchers have put extensive efforts to further study and develop adsorption refrigeration system to enhance the COP. A family of the new composite adsorbents formed by impregnating inorganic salts into the pores of zeolite has been developed $[1,2]$. Chan et al. reported that a $13 \mathrm{X} / \mathrm{CaCl}_{2}$ composite adsorbent for adsorption cooling systems with an ideal COP for a $13 \mathrm{X} / \mathrm{CaCl}_{2}$-water pair is 0.78 compared to 0.54 for zeolite-13X-water pair [4]. Similarly, Grenier et al. [5] studied a system using a $20 \mathrm{~m}^{2}$ simple solar collector containing $360 \mathrm{~kg}$ of $\mathrm{NaX}$ zeolite for a cold storage plant: it transferred only about $1.88 \mathrm{MJ} / \mathrm{m}^{2}$ when the incident radiation was $17.8 \mathrm{KJ} / \mathrm{m}^{2}$. The operation conditions were a $305 \mathrm{~K}$ condensation temperature, $274 \mathrm{~K}$ evaporating temperature, and $391 \mathrm{~K}$ regeneration temperature. The system could attain a net solar COP of 0.11 , while its cycle COP was 0.38 . Tatlier and Erdem-Şenatalar also used zeolite-water as working pair and reported that the system could operate successfully if the ambient temperature is less than $293 \mathrm{~K}$ [6]. Pons and Guilleminot tried to use zeolite composites to replace zeolite as an adsorbent and two different composites: 
(i) $65 \%$ zeolite $+35 \%$ metallic foam and (ii) $70 \%$ zeolite $+30 \%$ natural expanded graphite. The latter combination performed better [7]. A similar performance was noted by $\mathrm{Hu}$ et al. who found that if the evaporation temperature is set to $269 \mathrm{~K}$, the required condition temperature should not exceed $303 \mathrm{~K}$ [8].

Biloe et al. used polyvinyl alcohol mixed with polyethylene glycol as bonding agent and graphite mixed with activated carbon as adsorbent in a methane adsorption system. They found that adsorption of methane was improved due to the increased ratio of graphite [9]. Restuccia et al. [10] used 20\% bentonite as bonding agent for zeolite Y particles to enhance heat transfer in a heat exchange tube. They found that bentonite had no effect on adsorption of zeolite $\mathrm{Y}$ and improved heat transfer rate. Zhao et al. [11] investigated zeolite $13 \mathrm{X}$ by loading sodium silicate in different portions for an adsorption system. They found that an increased level of sodium silicate led to increased heat transfer. In addition, $\mathrm{Hu}$ et al. developed an adsorption system using heat from an exhaust pipe with an adsorption device based on zeolite mixed with aluminium. They found that zeolite-aluminium foam augmented the COP of an adsorption system compared to zeolite alone [8].

Our present work investigated experimentally the adsorption capacity of water on zeolite-4A from Thai clay with silver and copper loading to determine the COP for adsorption and desorption processes.

\section{Materials and Methods}

2.1. Raw Material. Clay was supplied by Mineral Resources Development Co., Ltd., sourced from Ranong, Thailand $\left(9^{\circ} 57^{\prime} 43^{\prime \prime} \mathrm{N} 98^{\circ} 38^{\prime} 20^{\prime \prime} \mathrm{E}\right)$. Laboratory Reagent (LR) grade sodium hydroxide was used for ion exchange procedure.

2.2. Preparation of Zeolite Type-4A. Zeolite-4A was synthesized from clay in two processes, metakaolinisation and zeolitisation, following Chandrasekhar et al. [12].

Metakaolinisation heats the clay to a high temperature until it transforms its crystal structure and turns into metakaolinite. Zeolitisation drives $\mathrm{Na}^{+}$ions into the crystal structure to form zeolite-4A.

For our experiments, we performed synthesis by calcination at $873 \mathrm{~K}$ for $3 \mathrm{~h}$ until the clay turned into metakaolinite. Then, $0.5 \mathrm{~kg}$ of metakaolinite was mixed with $2.5 \mathrm{~L}$ of $3.5 \mathrm{M}$ sodium hydroxide at $363 \mathrm{~K}$ for $3 \mathrm{~h}$ to insert $\mathrm{Na}^{+}$ions into the metakaolinite structure. The slurry of metakaolinite was then filtered and washed several times with distilled water to remove excess unreacted $\mathrm{NaOH}$. Then, it was filtered again and dried in an air oven at $373 \mathrm{~K}$ overnight. We had studied the maximum yield (70\%) in previous work [13]. Therefore, the preparation was done in the same condition before metal loading in this work. The chemical reaction in this step is

$$
\begin{aligned}
& 2 \mathrm{Al}_{2} \mathrm{Si}_{2} \mathrm{O}_{5}(\mathrm{OH})_{4} \longrightarrow 2 \mathrm{Al}_{2} \mathrm{Si}_{2} \mathrm{O}_{7}+4 \mathrm{H}_{2} \mathrm{O} \\
& 6 \mathrm{Al}_{2} \mathrm{Si}_{2} \mathrm{O}_{7}+12 \mathrm{NaOH} \\
& \quad \longrightarrow \mathrm{Na}_{12}\left(\mathrm{AlO}_{2}\right)_{12}\left(\mathrm{SiO}_{2}\right)_{12} \cdot 27 \mathrm{H}_{2} \mathrm{O}+6 \mathrm{H}_{2} \mathrm{O}
\end{aligned}
$$

2.3. Preparation of Metal-Impregnated Zeolite-4A. $0.5 \mathrm{~kg}$ of zeolite-4A was mixed with $2.5 \mathrm{~L}$ of silver nitrate or copper sulfate solution at the desired concentration at $323 \mathrm{~K}$ for 30 mins. After that, the mixture was dried at $343 \mathrm{~K}$ for 4 days. Finally, the calcined material was heated at $573 \mathrm{~K}$ for $2 \mathrm{~h}$.

2.4. Characterization of Raw Material and Zeolite-4A. Chemical compositions of raw kaolin samples were determined by X-ray fluorescence spectroscopy using a Bruker AXS SRS 3400 .

The crystallinity of the inorganic components was analyzed by XRD (Bruker D8, Germany) with $\mathrm{Cu}-\mathrm{K}_{\alpha}$ radiation used to record the diffraction spectra. The tube voltage and current were $30 \mathrm{kV}$ and $30 \mathrm{~mA}$. The area of 8 strong diffraction peaks of the sample was compared to the pattern of standard zeolite which was set to be $100 \%$.

The morphology of samples was observed using a Scanning Electron Microscope (Leo 1455 VP, UK), using an accelerating voltage of $15 \mathrm{kV}$.

Brunauer-Emmett-Teller (BET) analysis used a Micromeritics surface analyzer (ASAP2020, USA) to determine the specific surface area of the zeolite and the pore size was calculated by the Barrett-Joyner-Halenda (BJH) method via desorption-adsorption of nitrogen gas at $78 \mathrm{~K}$.

2.5. Basic Adsorption Cycle. A complete adsorption cooling cycle that consists of adsorption (evaporation + cooling) and desorption (condensation + heating) can be explained with the help of the Clapeyron diagram in Figure 1. The idealized cycle begins at point 1 where the maximum amount of refrigerant is adsorbed. The adsorbent is at low temperature and low pressure at point 1 . Along line 1-2, the adsorbent is heated and desorbs refrigerant vapor isosterically. This step is isosteric, because there will be no refrigerant flow until the pressure inside the adsorbent bed becomes equal to or greater than the pressure of the condenser and the amount of desorbed refrigerant is small relative to the total amount adsorbed. Continued heating (line 2-3) desorbs more refrigerant, forcing it to the condenser until state 3 is attained, at which desorption ceases. This second step is isobaric desorption. Then, the hot adsorbent is cooled isosterically causing adsorption and depressurization (line 3-4). When the pressure drops below $P_{\mathrm{ev}}$, refrigerant in the evaporator starts to boil and flows to the adsorbent bed, producing the cooling effect. Cooling of the adsorbent continues until the bed is saturated with refrigerant, completing the cycle. This process (line 4-1) is isobaric adsorption.

The COP of the system can be calculated as reported in Cacciola and Restuccia [14]. As seen from Figure 1, the thermodynamic cycle consists of 4 processes:

$1 \rightarrow 2$ isosteric heating (constant concentration).

$2 \rightarrow 3$ isobaric desorption (heat of desorption + sensible heating).

$3 \rightarrow 4$ isosteric cooling (constant concentration).

$4 \rightarrow 1$ isobaric adsorption (heat of adsorption + sensible cooling). 


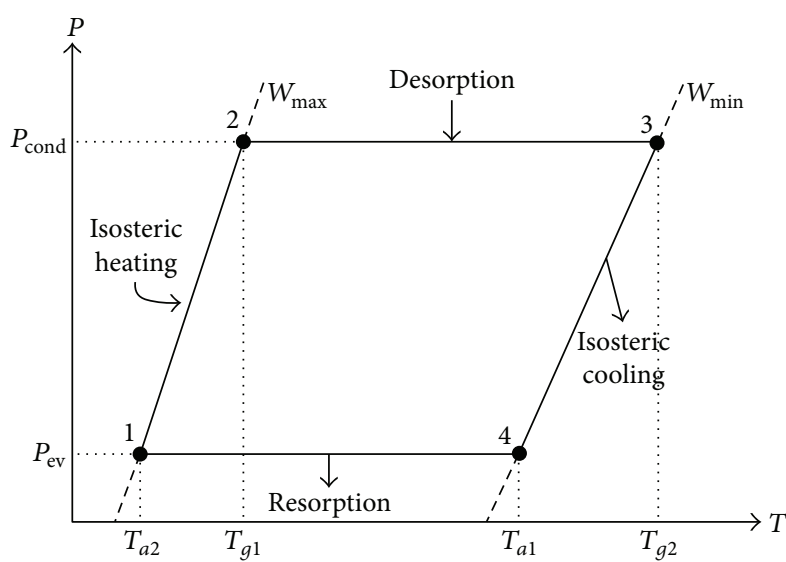

Figure 1: $P-T-W$ diagram of the basic adsorption cycle [14].

In isosteric heating $(1 \rightarrow 2)$ and isobaric desorption $(2 \rightarrow$ 3 ) heat is added to the adsorbent bed. The heat supplied to the adsorbent bed for its isosteric heating $(1 \rightarrow 2)$ is

$$
Q_{12}=m_{z}\left(C_{p z}+C_{p w} W_{\max }\right)\left(T_{g 1}-T_{a 2}\right),
$$

where $m_{z}$ is the mass of adsorbent in $\mathrm{kg}, C_{p z}$ is the specific heat of adsorbent in $\mathrm{kJ} / \mathrm{kg}-\mathrm{K}$, and $C_{p w}$ is the specific heat of adsorbate in the adsorbed phase in $\mathrm{kJ} / \mathrm{kg}-\mathrm{K}$.

The heat necessary for the desorption phase $(2 \rightarrow 3)$ has two components:

$$
Q_{23}=Q_{\mathrm{des}}+Q_{s d}
$$

where $Q_{\text {des }}$ is the heat of desorption:

$$
Q_{\mathrm{des}}=m_{z} \Delta H\left(W_{\max }-W_{\min }\right)
$$

and $Q_{s d}$ is the sensible heat of adsorbent plus its adsorbate content:

$$
Q_{s d}=m_{z} C_{p z}\left(T_{g 2}-T_{g 1}\right)+m_{z} C_{p w} \omega\left(T_{g 2}-T_{g 1}\right) .
$$

The useful refrigeration effect, which is the energy that must be supplied to the evaporator, $Q_{e}$, is calculated as the latent heat of evaporation of the cycled adsorbate, minus the sensible heat of the adsorbate that is entering the evaporator at condensation temperature:

$$
Q_{e}=m_{z}\left(W_{\max }-W_{\min }\right)\left[L-C_{p l}\left(T_{c}-T_{e}\right)\right]
$$

where $C_{p l}$ is the specific heat of adsorbate in liquid phase and $L$ is the heat of evaporation of adsorbate in $\mathrm{kJ} / \mathrm{kg}$.

From the previous equations, the COP for cooling operation can be calculated as the ratio of useful refrigeration effect produced and heat input to the adsorbent bed:

$$
\mathrm{COP}=\frac{Q_{e}}{Q_{12}+Q_{23}} .
$$

TABLE 1: Chemical composition of clay at Ranong province.

\begin{tabular}{lcccccc}
\hline Component & $\mathrm{SiO}_{2}$ & $\mathrm{Al}_{2} \mathrm{O}_{3}$ & $\mathrm{SO}_{3}$ & $\mathrm{~K}_{2} \mathrm{O}$ & $\mathrm{Fe}_{2} \mathrm{O}_{3}$ & $\mathrm{CuO}$ \\
\hline \% weight & 52.2 & 43.3 & 0.36 & 2.18 & 1.61 & 0.25 \\
\hline
\end{tabular}

2.6. Experimental Setup. Before starting the experiments, the laboratory was prepared according to the procedure given by Cacciola and Restuccia [14]. An overview of the rig components is shown in Figure 2. A known mass of zeolite was put into the adsorber. The adsorber line was connected to the evaporator and condenser line.

System preparation steps, before activating the system, are as follows:

(1) Turn off every valve.

(2) Put $0.1 \mathrm{~kg}$ of zeolites into adsorber.

(3) Put 0.3 L of water into evaporator.

(4) Adjust vacuum pressure value of evaporator at $73 \mathrm{kPa}$.

(5) For adsorber and condenser, adjust vacuum pressure value at $87 \mathrm{kPa}$ within 20 mins.

Desorption system tests are as follows:

(1) Valve $V_{1}$ opened slowly to allow the water vapor to flow into the adsorber for 30 mins after which the system reaches thermodynamic equilibrium of adsorption.

(2) Turn off valve $V_{1}$

(3) Then, begin desorption process by generating heat for adsorber at the designated temperature.

(4) After that, turn on valves $V_{2}, V_{3}$, and $V_{4}$ to allow the water vapor into condenser which contains refrigerant to condense vapor into liquid.

(5) Collectively store it at evaporator for 30 mins after which the system reaches thermodynamic equilibrium of desorption process.

(6) All valves closed.

Adsorption system testing: valve $\mathrm{V}_{1}$ opened slowly to allow the water vapor to flow into the adsorber for 30 mins after which the system reaches thermodynamic equilibrium of adsorption process and turn off valve $V_{1}$.

For all steps, temperature was recorded by a data logger. The total amount of water desorbed and adsorbed by zeolite was read from the balance.

\section{Results and Discussions}

3.1. Properties of Zeolite-4A. The chemical composition of clay from Ranong province in Thailand is in Table 1. The main components of the clay samples were oxides of $\mathrm{Si}$ and $\mathrm{Al}$, but they contain sulfur, potassium, iron, and copper impurities. Therefore, zeolite-4A prepared from this clay is always contaminated with these elements.

The XRD patterns of the solid samples are shown and compared to the pattern of standard zeolite in Figure 3: it can 


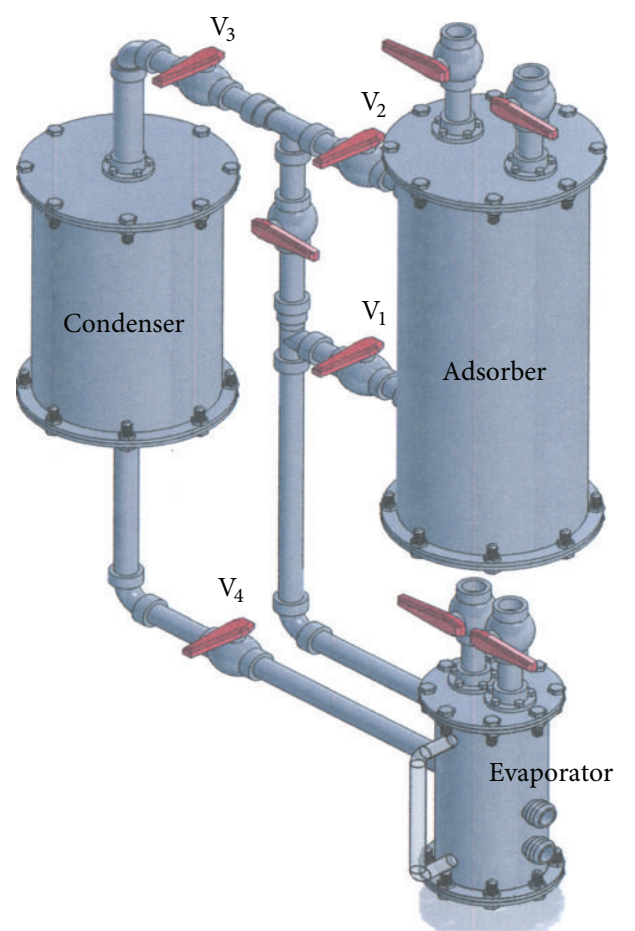

Figure 2: Photograph of adsorption refrigeration system.

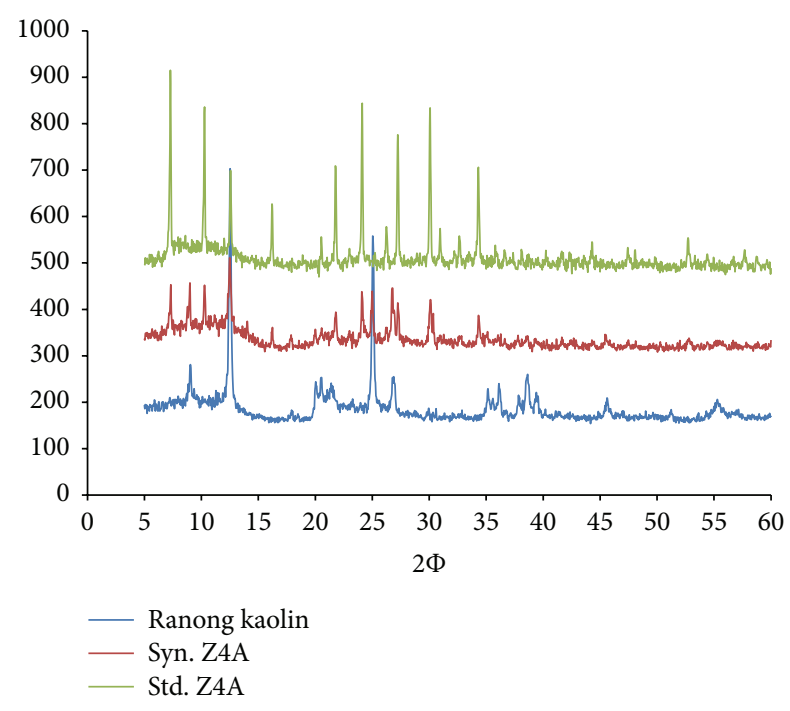

FIGURE 3: X-ray diffraction patterns of clay and zeolite-4A.

be seen that synthesized clay for zeolite-4A (Z4A) comprises kaolinite as main element and when it was heated at $773 \mathrm{~K}$, kaolinite became more crystalized showing a higher peak value, because organic compounds had evaporated at $773 \mathrm{~K}$ and made kaolinite purer. Also, peak was found along 2 axes at the same position as a zeolite- $4 \mathrm{~A}$ reference, so we concluded that clay was transformed to zeolite- $4 \mathrm{~A}$.

When examining microstructure attributes of clay using Scanning Electron Microscope (SEM), we found crystalline structures arranged in layers; see Figure 4(a). Figure 4(b) shows the prepared zeolite- $4 \mathrm{~A}$ which has crystalline angles
TABLE 2: Specific surface area, total pore volume, and average pore diameter.

\begin{tabular}{lccc}
\hline Properties & $S_{\text {BET }}\left(\mathrm{m}^{2} / \mathrm{g}\right)$ & $\begin{array}{c}\text { Total pore } \\
\text { volume }\left(\mathrm{mm}^{3} / \mathrm{g}\right)\end{array}$ & $\begin{array}{c}\text { Average pore } \\
\text { diameter }(\mathrm{nm})\end{array}$ \\
\hline Z4A & 6.14 & 7.3 & 4.81 \\
$\mathrm{Cu} 4 \% / \mathrm{Z} 4 \mathrm{~A}$ & 12.7 & 28.3 & 8.92 \\
$\mathrm{Cu} \% / \mathrm{ZAA}$ & 18.2 & 42.7 & 9.39 \\
$\mathrm{Ag} 4 \% / \mathrm{Z} 4 \mathrm{~A}$ & 17.9 & 26.2 & 5.86 \\
Ag15\%/Z4A & 15.9 & 21.1 & 5.30 \\
\hline
\end{tabular}

that corresponded with sharp peaks in the XRD spectrum having the crystalline attributes of zeolite- $4 \mathrm{~A}$.

Figure 5 shows the zeolite- $4 \mathrm{~A}$ surface filled with copper $(\mathrm{Cu} 6 \% / \mathrm{Z} 4 \mathrm{~A})$ (a) and silver (Ag15\%/Z4A) (b) at 5,000x magnification. It can be clearly seen that silver particles were thinly dispersed on the zeolite-4A surface, whereas copper particles aggregated into larger clumps on the surface (a).

Synthesized zeolite-4A was analyzed for quality of porosity using adsorption of nitrogen at $78 \mathrm{~K}$ with Micromeritics chemisorption analyzer model ASAP2020. Pore surface area was determined using the Brunauer-Emmett-Teller (BET) formula to total pore volume at $P / P_{o}=0.97$ and average pore diameter calculated by equation $(4 \times$ total pore volume)/surface.

Figure 6 shows the $\mathrm{N}_{2}$ adsorption isotherm of zeolite- $4 \mathrm{~A}$ at $78 \mathrm{~K}$ which indicated that the adsorption isotherm was similar to type IV in the nomenclature IUPAC for mesoporous materials. Table 2 shows that, for synthesized zeolite-4A, when sodium ions $\left(\mathrm{Na}^{+}\right)$were replaced with copper $\left(\mathrm{Cu}^{2+}\right)$ or silver $\left(\mathrm{Ag}^{+}\right)$ions, the total pore volume and pore diameter increased relatively to pure zeolite-4A. Cu6\%/Z4A showed the highest value for surface area $\left(18.2 \mathrm{~m}^{2} / \mathrm{g}\right)$, total pore volume $(0.0428 \mathrm{~mL} / \mathrm{g})$, and average pore diameter $(9.39 \mathrm{~nm})$. IUPAC defines three types of pore diameter: micropore $(<2 \mathrm{~nm})$, mesopore $(2-50 \mathrm{~nm})$, and macropore $(>50 \mathrm{~nm})$. Our analysis showed that all synthesized zeolite-4A samples were mesopore and this indicates that this zeolite- $4 \mathrm{~A}$ could adsorb water with diameter $0.28 \mathrm{~nm}$ and average pore, smaller than the diameter of all zeolites.

3.2. Adsorption and Desorption Behavior. Testing adsorption under vacuum conditions involved two processes: adsorption and desorption. Five samples of synthesized adsorbent were tested: $\mathrm{Z} 4 \mathrm{~A}, \mathrm{Cu} 4 \% / \mathrm{Z} 4 \mathrm{~A}, \mathrm{Cu} 6 \% / \mathrm{Z} 4 \mathrm{~A}, \mathrm{Ag} 4 \% / \mathrm{Z} 4 \mathrm{~A}$, and Ag15\%/Z4A. Maximum adsorption $\left(W_{\max }\right)$ and minimum adsorption $\left(W_{\min }\right)$ of zeolite-4A are shown in Figures 7-9.

Physical adsorption depended on pore diameter and pore volume. Generally, good adsorption occurred at low temperature due to the exothermic process. So when the temperature was increased, the degree of adsorption decreased. Figure 7 shows the water adsorption mass during adsorption: we found that when the adsorber temperature increased, adsorption performance of water decreased from 0.08 at $315 \mathrm{~K}$ to 0.03 at $318 \mathrm{~K}$ and the COP reduced correspondingly.

During evaporation after providing heat to adsorber at temperatures from 393 to $478 \mathrm{~K}$ for $30 \mathrm{mins}$, heat from 


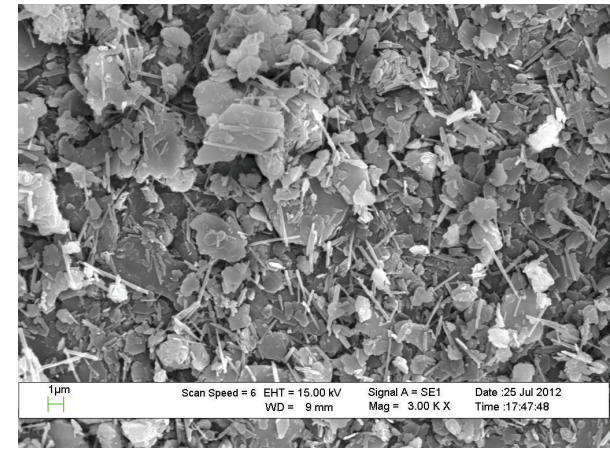

(a)

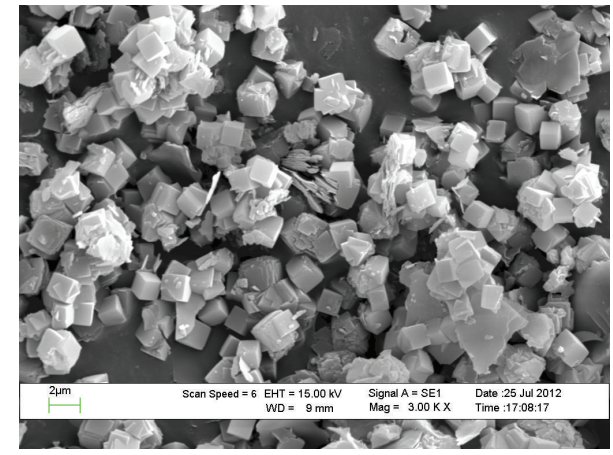

(b)

FIGURE 4: SEM photograph of clay (a) and zeolite-4A (b).

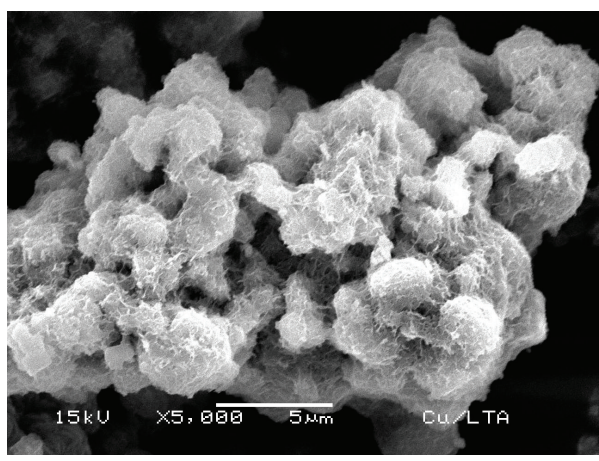

(a)

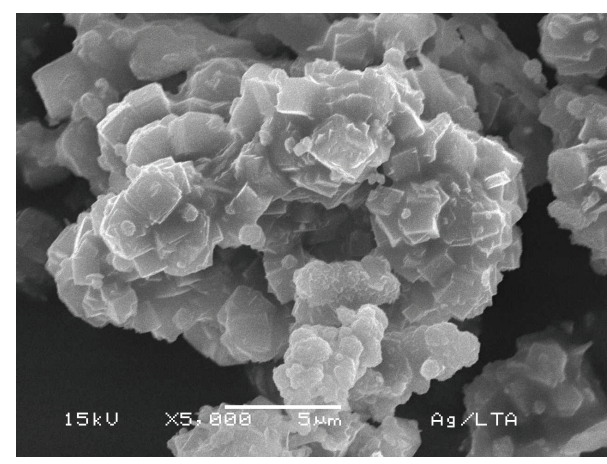

(b)

Figure 5: SEM of Cu6\%/Z4A (a) and Ag15\%/Z4A (b).

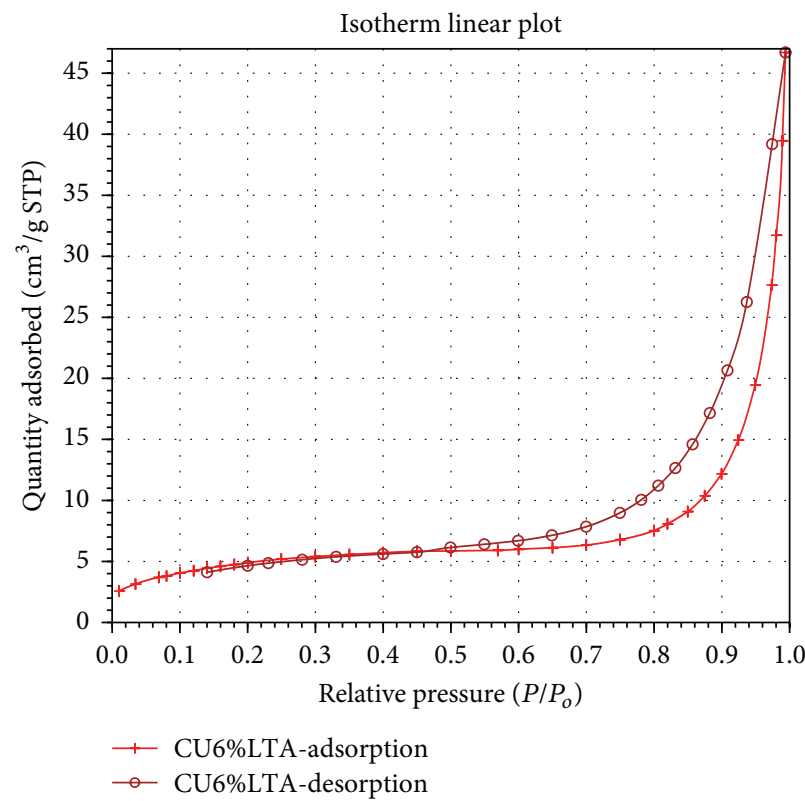

(a)

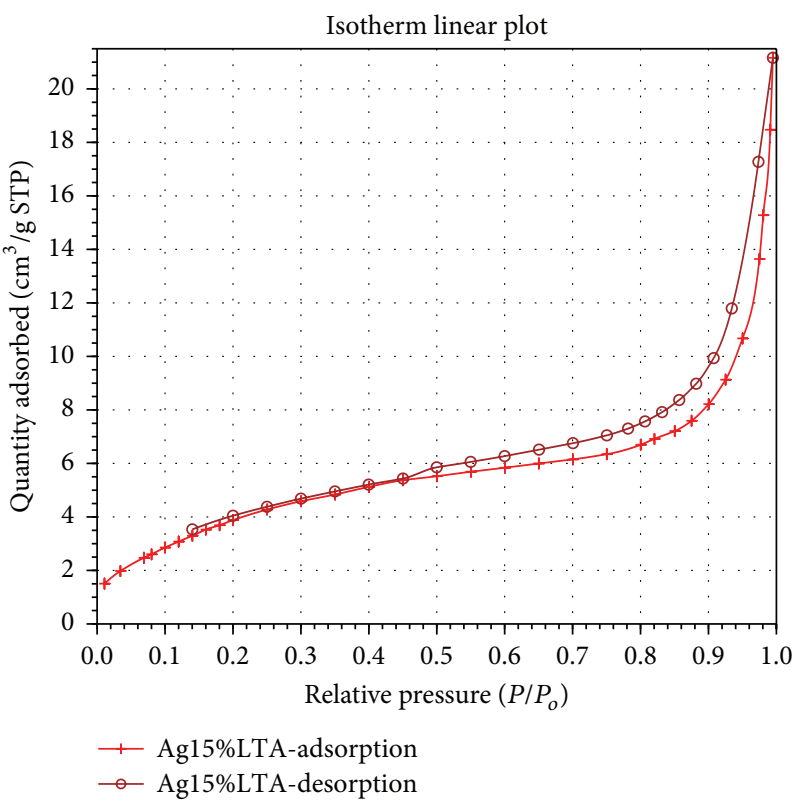

(b)

Figure 6: Isotherms for Cu6\%/Z4A (a) and Ag15\%/Z4A (b). 


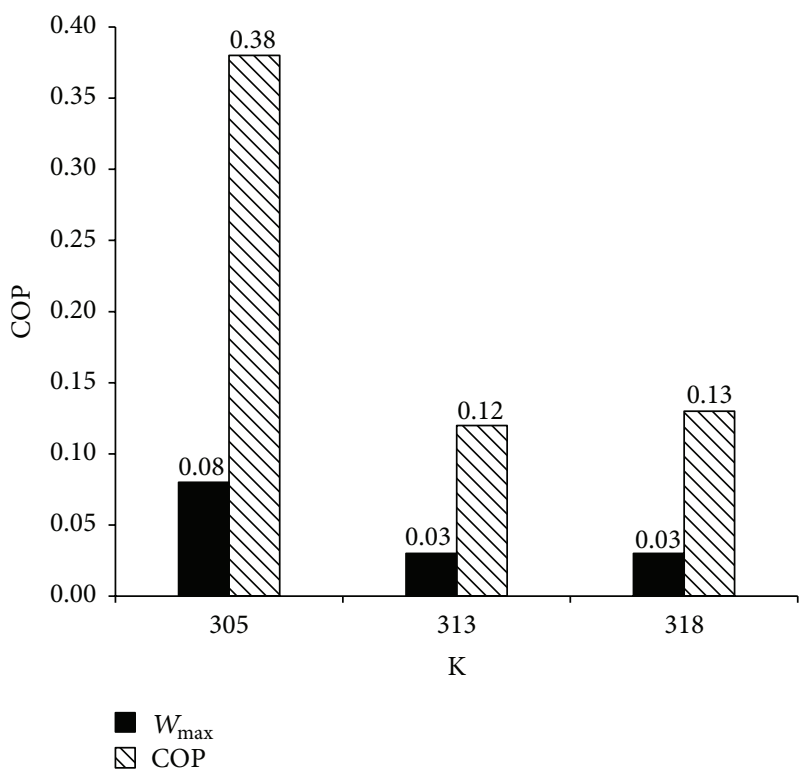

FIGURE 7: Effect of adsorption temperature on $W_{\max }$ and COP.

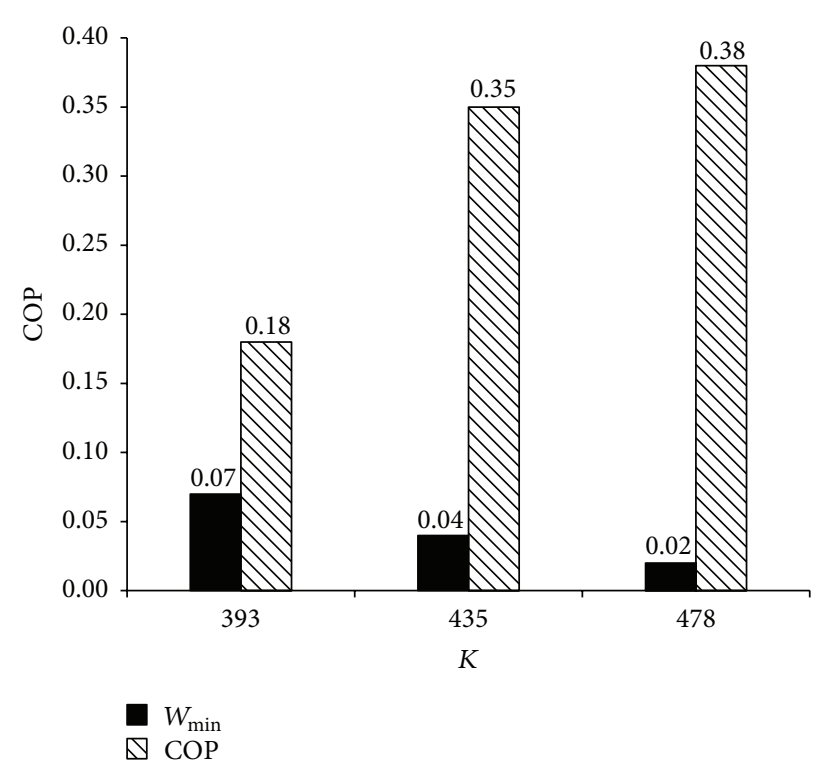

Figure 8: Effect of desorption temperature on $W_{\min }$ and COP.

adsorber was transferred to zeolite-4A until it reached the stable stage. After that, vapor was expelled from the zeolite$4 \mathrm{~A}$ and shifted to condenser; vapor condensed and collected in the evaporator.

From Figure 8, we see the lowest adsorption weight for working pairs (zeolite-4A and water); it was found that heat must be increasingly supplied for adsorber at $478 \mathrm{~K}$ to gain the maximum evaporation from zeolite. Kinetic energy of vapor held unequal value when temperature changed. When the temperature increased, vapor mobility increased, so better desorption performance was observed. Water was evaporated faster from adsorber during desorption and a higher water volume was adsorbed in the absorption step.

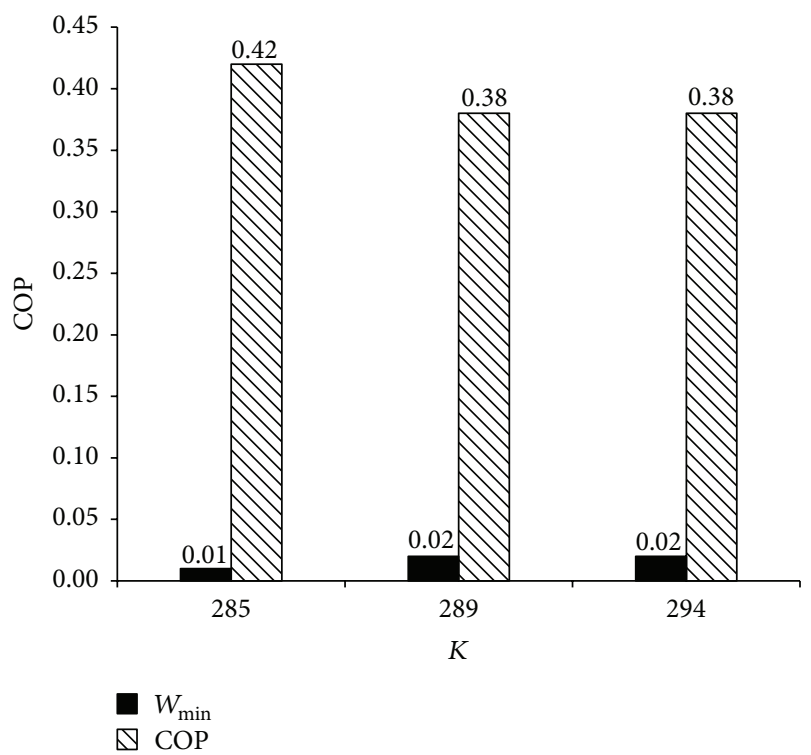

FIGURE 9: Effect of condenser temperature on $W_{\min }$ and COP.

Figure 9 shows that the water mass adsorbed during the exothermic process was little effected by temperature between 285 and $294 \mathrm{~K}$. Water molecules adsorbed in the zeolite- $4 \mathrm{~A}$ pores could be condensed to liquid at a temperature higher than boiling point in the process called capillary condensation. When the condensation temperature increased, the saturated vapor pressure within the condenser was also increased blocking (or hindering) transfer of vapor into the condenser. This led to ineffective desorption and the mass of vapor being desorbed was also reduced. These results were based on a small-scale experiment, so the adsorbed water mass and COP showed little significant difference between 285 and $294 \mathrm{~K}$; therefore, to save energy in vapor condensation step, the condensation temperature was set to match the very slightly larger COP at $294 \mathrm{~K}$.

3.3. COP of Adsorption Cooling System. Investigating adsorption cooling system using referential equation of Cacciola and Restuccia [14] could determine the COP of the system. The parameters obtained from maximum and minimum adsorption were adsorber at $305 \mathrm{~K}$ during adsorption and adsorber at $478 \mathrm{~K}$ during desorption.

Figure 10 shows that copper and silver added to the zeolite-4A significantly affected system COP because a higher mass of water was adsorbed by copper or silver filled zeolite$4 \mathrm{~A}$ compared to pure zeolite- $4 \mathrm{~A}$. This maximum adsorption $\left(W_{\max }\right)$ was increased because size and volume of pores were also increased. However, minimum adsorption $\left(W_{\min }\right)$ showed no significant difference because the increase of average pore diameter allowed vapor to be evaporated easily from the pores when receiving heat at temperature higher than the boiling point. Our results showed that COPs were 0.56 for $\mathrm{Cu} 6 \% / \mathrm{Z} 4 \mathrm{~A}$ and 0.52 for Ag15\%/Z4A, whereas COP of Z4A was only 0.38 showing that adding copper and silver effectively increased the system COP. COP of zeolite-4A filled with $\mathrm{Cu}$ yielded higher value than zeolite-4A filled with $\mathrm{Ag}$. 


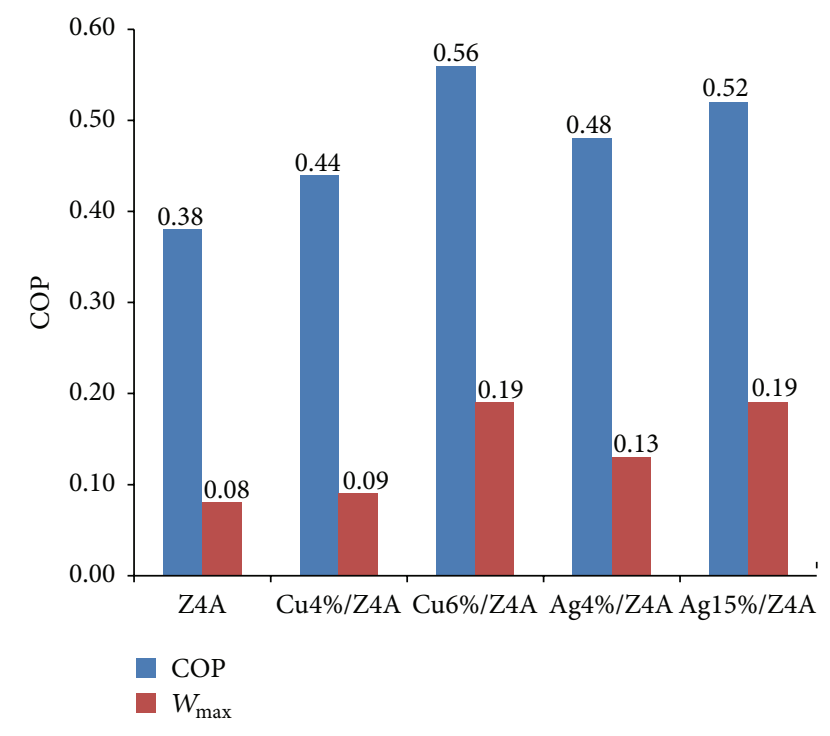

Figure 10: Effect of zeolite type COP.

This is because of the ion exchange between sodium ion $\left(\mathrm{Na}^{+}\right)$and cations of metal. Copper ion was divalent cation that could balance framework negative charge for 2 sites. However, silver ion was monovalent cation that could balance only 1 site. Two sites' exchange (copper ion) resulted in lower number of exchangeable cations in zeolite structure, higher pore volume, and higher adsorption capacity. Considering the size of atoms and ions, it was found that silver ion $\left(\mathrm{Ag}^{+}\right.$, $126 \mathrm{pm})$ is not different than silver atom $(\mathrm{Ag}, 144 \mathrm{pm})$, while the size of the copper ion $\left(\mathrm{Cu}^{2+}, 72 \mathrm{pm}\right)$ is more different than copper atom $(\mathrm{Cu}, 128 \mathrm{pm})$. The BET method of both pure and metal loaded zeolite-4A samples is given in Table 2. The increase in the loading of silver in zeolite-4A causes a decrease in the surface area due to obstruction of active site of zeolite by large size of silver ion. The decrease in the pore volume by silver loading is in agreement with the surface area measurements. An increase in the surface area was observed for copper loading when the copper amounts exceeded a certain critical value. This increase in the surface area is suspected to be due to the phase separation of the copper precursors after a critical loading. The data also shows that $\mathrm{Cu}^{2+}$ is twice smaller than $\mathrm{Ag}^{+}$. So this affected the maximum adsorption of water by $\mathrm{Cu} 6 \% / \mathrm{Z} 4 \mathrm{~A}$ in higher volume compared to Ag15\%/Z4A.

\section{Conclusions}

We were able to use Thai clay to synthesize zeolite-4A by converting it into metakaolinite via calcination at $873 \mathrm{~K}$ and activation by $3.5 \mathrm{~mol} / \mathrm{L} \mathrm{NaOH}$ with more than $70 \%$ yields.

In testing performance of COP systems, we found that the temperature of the adsorber and condenser affected the COP. That is, in the adsorption step, as adsorber temperature increased, adsorption was reduced decreasing COP of the system. In desorption, when adsorber temperature increased, a higher mass of refrigerant was desorbed leading to better system COP.
Moreover, zeolite filled with copper and silver enhances system COP relative to pure zeolite, because copper and silver increase pore volume which empowers water adsorption, which results in fast and efficient desorption of water and leads to better system COP.

\section{Nomenclature}

$C_{p l}$ : Specific heat of adsorbate in liquid phase

$C_{p w}$ : Specific heat of adsorbate in adsorbed phase

$C_{p z}:$ Specific heat of adsorbent

COP: Coefficient of Performance

$\Delta H$ : Heat of desorption of adsorbate

$\mathrm{K}: \quad$ Kelvin temperature scale

$L: \quad$ Heat of evaporation of adsorbate

$m_{z}: \quad$ Mass of adsorbent

$Q_{\text {des }}:$ Heat of desorption

$Q_{e}: \quad$ Heat of produced cooling system

$Q_{s d}:$ The sensible heat of adsorbent

$T_{a 1}: \quad$ Initial adsorption temperature

$T_{a 2}$ : Final adsorption temperature

$T_{c}: \quad$ Inside condenser temperature

$T_{e}$ : Inside evaporator temperature

$T_{g 1}: \quad$ Initial desorption temperature

$T_{g 2}$ : Final desorption temperature

$W_{\text {max }}$ : Maximum adsorption performance

$W_{\min }$ : Minimum adsorption performance

$\omega: \quad$ Average adsorption performance.

\section{Competing Interests}

The authors declare that they have no competing interests.

\section{Acknowledgments}

The authors thank Miss Warunee Yuthphan, Mineral Resources Development Co., Ltd., for providing Ranong clay, the Department of Chemistry, King Mongkut's Institute of Technology Ladkrabang for acquiring the XDF, XRD, and SEM data, and Energy Policy and Planning Office, Ministry of Energy, Royal Thai Government, for financial support.

\section{References}

[1] D. C. Wang, Y. H. Li, D. Li, Y. Z. Xia, and J. P. Zhang, "A review on adsorption refrigeration technology and adsorption deterioration in physical adsorption systems," Renewable and Sustainable Energy Reviews, vol. 14, no. 1, pp. 344-353, 2010.

[2] L. W. Wang, R. Z. Wang, and R. G. Oliveira, "A review on adsorption working pairs for refrigeration," Renewable and Sustainable Energy Reviews, vol. 13, no. 3, pp. 518-534, 2009.

[3] E. E. Anyanwu, "Review of solid adsorption solar refrigeration II: an overview of the principles and theory," Energy Conversion and Management, vol. 45, no. 7-8, pp. 1279-1295, 2004.

[4] K. C. Chan, C. Y. H. Chao, G. N. Sze-To, and K. S. Hui, "Performance predictions for a new zeolite $13 \mathrm{X} / \mathrm{CaCl}_{2} \mathrm{com}$ posite adsorbent for adsorption cooling systems," International Journal of Heat and Mass Transfer, vol. 55, no. 11-12, pp. 32143224, 2012. 
[5] P. H. Grenier, J. J. Guilleminot, F. Meunier, and M. Pons, "Solar powered solid adsorption cold store," ASME Journal of Solar Energy Engineering, vol. 110, no. 3, pp. 192-197, 1988.

[6] M. Tatlier and A. Erdem-Şenatalar, "The effects of thermal gradients in a solar adsorption heat pump utilizing the zeolitewater pair," Applied Thermal Engineering, vol. 19, no. 11, pp. 1157$1172,1999$.

[7] M. Pons and J. J. Guilleminot, "Design of an experimental solarpowered, solid-adsorption ice maker," Journal of Solar Energy Engineering, Transactions of the ASME, vol. 108, no. 4, pp. 332337, 1986.

[8] P. Hu, J.-J. Yao, and Z.-S. Chen, "Analysis for composite zeolite/foam aluminum-water mass recovery adsorption refrigeration system driven by engine exhaust heat," Energy Conversion and Management, vol. 50, no. 2, pp. 255-261, 2009.

[9] S. Biloe, V. Goetz, and S. Mauran, "Characterization of adsorbent composite blocks for methane storage," Carbon, vol. 39, no. 11, pp. 1653-1662, 2001.

[10] G. Restuccia, A. Freni, F. Russo, and S. Vasta, "Experimental investigation of a solid adsorption chiller based on a heat exchanger coated with hydrophobic zeolite," Applied Thermal Engineering, vol. 25, no. 10, pp. 1419-1428, 2005.

[11] H. Zhao, M. Zhang, J. Lv, G. Yu, and Z. Zou, "Thermal conductivities study of new types of compound adsorbents used in solar adsorption refrigeration," Energy Conversion and Management, vol. 50, no. 5, pp. 1244-1248, 2009.

[12] S. Chandrasekhar, P. Raghavan, G. Sebastian, and A. D. Damodaran, "Brightness improvement studies on 'kaolin based' zeolite 4A," Applied Clay Science, vol. 12, no. 3, pp. 221-231, 1997.

[13] S. Trisupakitti, J. Jamradloedluk, and S. Wiriyaumpaiwong, "Synthesis and characterization of 4A-zeolite devived from Thai kaolin," in Proceedings of the 5th International Conference on Science, Technology and Innovation for Sustainable Well-Being (STISWB V'13), September 2013.

[14] G. Cacciola and G. Restuccia, "Reversible adsorption heat pump: a thermodynamic model," International Journal of Refrigeration, vol. 18, no. 2, pp. 100-106, 1995. 

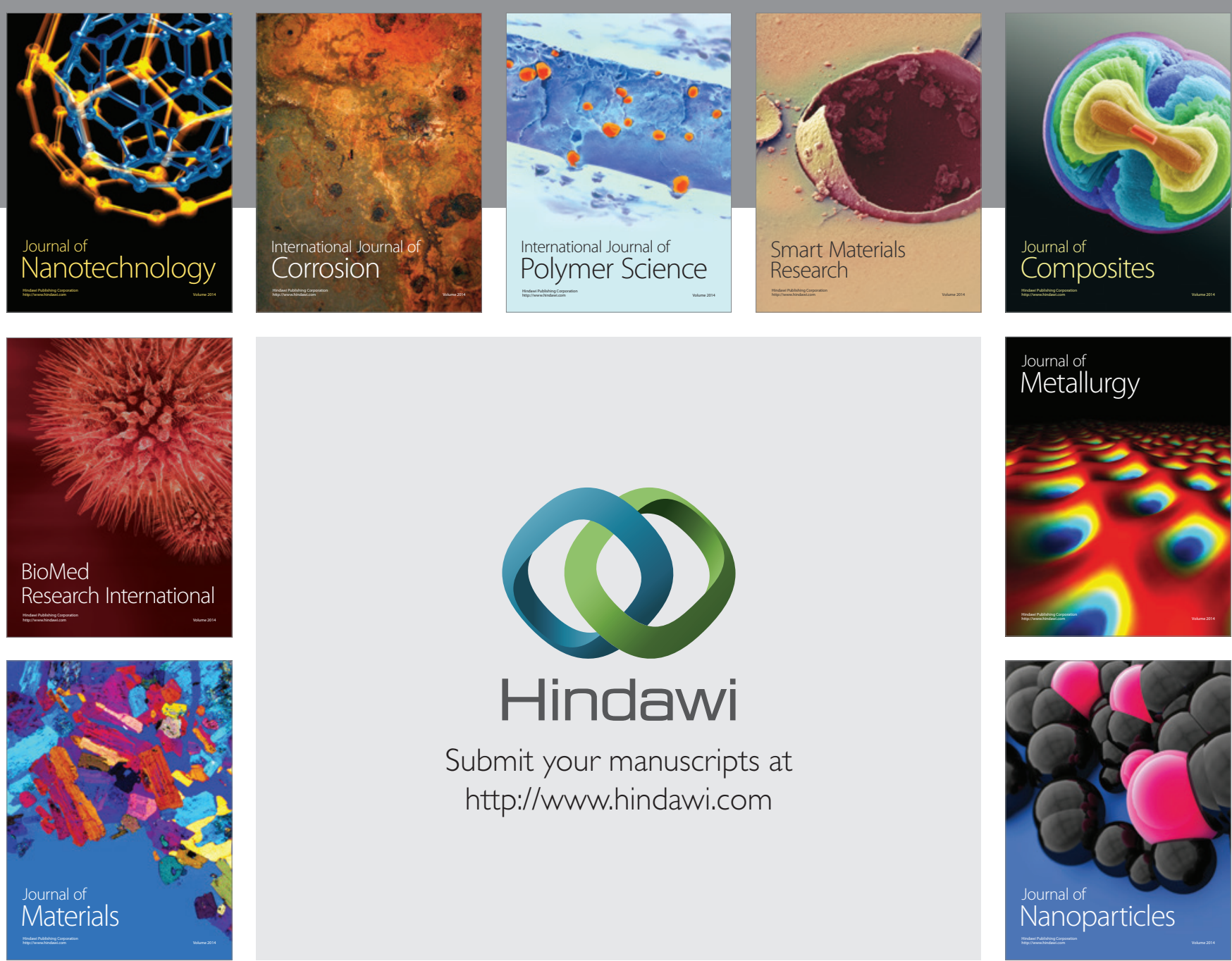

\section{Hindawi}

Submit your manuscripts at

http://www.hindawi.com

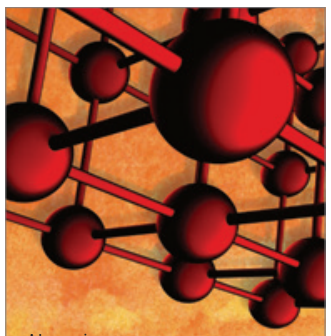

Materials Science and Engineering
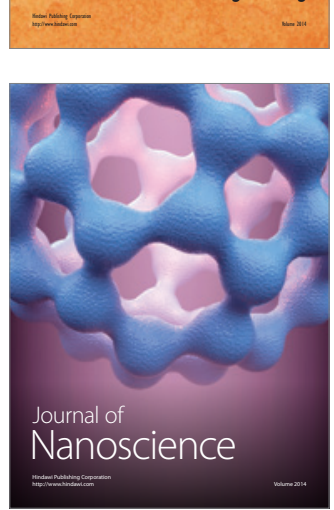
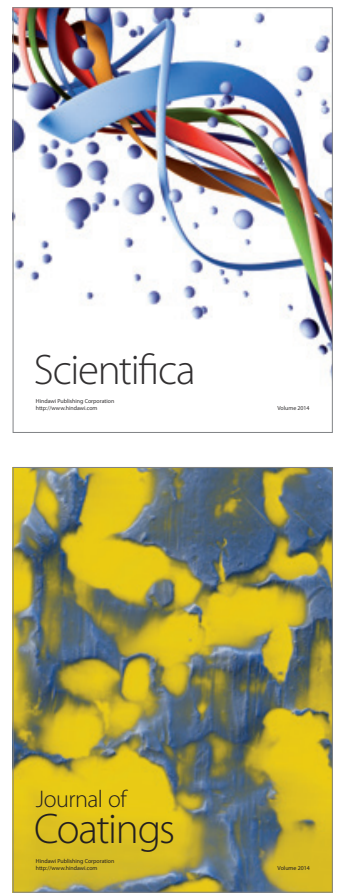
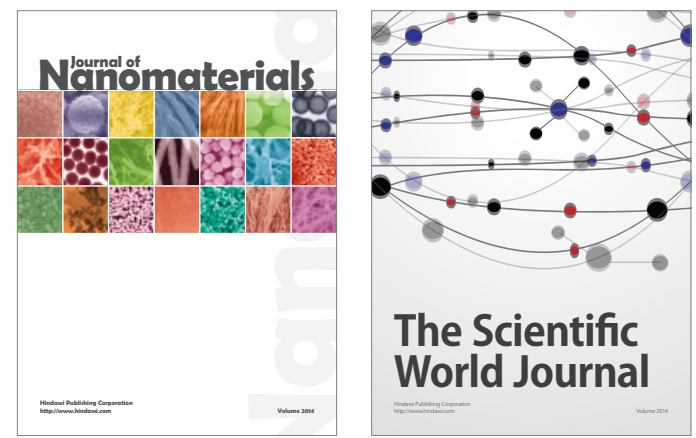

The Scientific World Journal
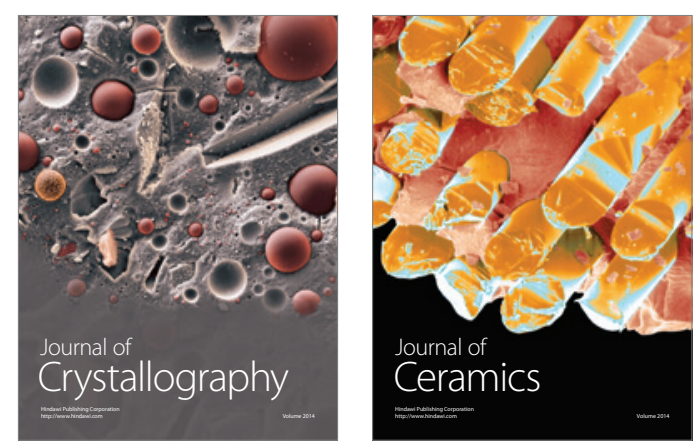
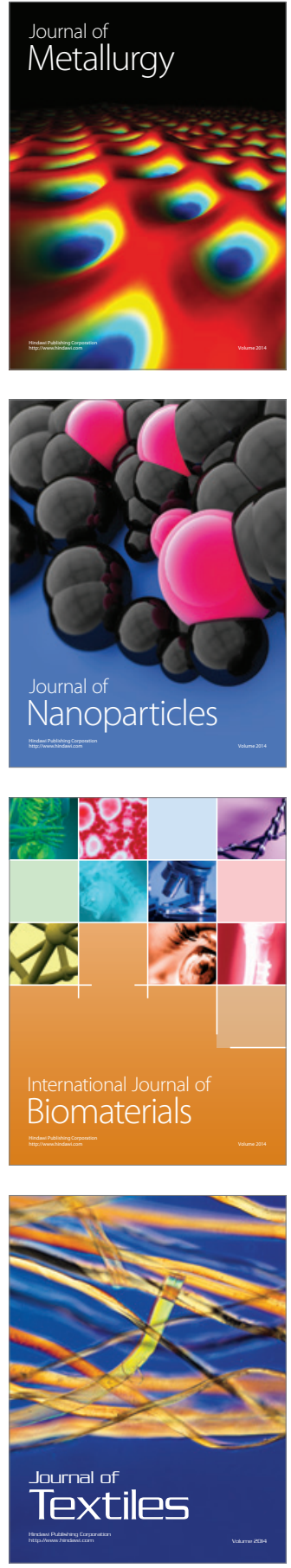